\title{
Sharpening the Ethnographer's Toolkit: Introducing the Freelist Method to Information Systems Research
}

\author{
Christopher B. Califf \\ Western Washington University \\ christopher.califf@wwu.edu
}

\author{
T. S. Stumpf \\ Humboldt State University \\ tyler.stumpf@humboldt.edu
}

\begin{abstract}
Ethnography has been presented as a promising research method for information systems researchers. However, IS research using ethnographic techniques still remains scant. We believe this has occurred for four primary reasons: (1) the techniques needed to conduct effective ethnographic research are often discussed in vague detail; (2) data collection in ethnographic studies is perceived as unfocused and unsystematic; (3) ethnographic studies are perceived as highly time consuming and thus impractical; and (4) IS researchers may not be well-versed in understanding how to make sense of the findings of an ethnographic analysis. In this paper, we address these constraints by introducing a well-established ethnographic method called freelisting to ethnographic research in IS. Specifically, we discuss the essence of freelisting, how it fits into ethnography, and provide an example of how to conduct and analyze a freelist in IS. The benefits of freelisting for IS researchers are also explained.
\end{abstract}

\section{Introduction}

The Information Systems (IS) discipline has a rich history of embracing diversity in its research methods. These methods are often associated with distinct paradigms, each with their own ontological, epistemological, and axiological conventions [1]-[6]. IS researchers must therefore be knowledgeable about and attentive to the assumptions, advantages, and obstacles associated with particular methods, and remain keenly aware of the circumstances under which adopting a certain approach is suitable for investigation [7]-[9].

Several review papers have identified the most widespread research methods in IS research [10][12]. While survey methods and descriptive case studies remain the most common [10], ethnography has been increasingly presented as a promising research method appropriate for an information systems context over the past two decades [7], [10], [13]. In 1995, Harvey and Myers stated that ethnographic research is "well suited to providing information systems researchers with rich insights into the human, social, and organizational aspects of information systems development and application" [14, p. 22]. Similarly, in 2004, Rennecker [15] advocated for acknowledging both the flexibility of ethnographic methods as well as the importance of adapting them to virtual contexts. In addition, ethnographic research has recently been touted for its potential to "make a powerful contribution in mixed method studies" [3, p. 166].

While ethnographic research in IS has indeed gained in popularity, and has helped some researchers develop valuable insights into IS phenomena, [16], [17], unfortunately, only a small number of ethnographic studies exist [13]. We believe this has occurred due to four primary reasons:

- The techniques needed to conduct effective ethnographic research are often vaguely discussed.

- Data collection in ethnographic studies is perceived as unfocused and unsystematic.

- Ethnographic research is perceived as highly time consuming and therefore impractical for many.

- IS researchers may not be well-versed in understanding how to make sense of the findings of an ethnographic analysis.

The purpose of this paper is to introduce and discuss a well-established ethnographic method called freelisting that may help to ameliorate the four reasons listed above [18]-[21]. Comparable to openended surveying, freelisting is a respected technique used in anthropology [22]. By asking individuals within a community to freely list several items related to a specific domain, freelisting can "amass focused data quickly and easily" $[19$, p. 1]. 
Freelisting is a method worthy of serious consideration by IS researchers for a variety of reasons. First, freelisting helps provide systematic focus and structure IS researchers need to consider effectively undertake ethnographic research. Second, freelisting can enable IS researchers to quickly collect and analyze data that they can use to uncover how individuals interpret the world. Third, freelisting is highly amenable to mixed-methods approaches [e.g., 23]. Fourth, freelisting can provide IS researchers with a novel methodological technique with which to revisit, and potentially develop additional insights into, field-specific theories in IS (e.g., the technology acceptance model). Fifth, freelisting can aid in more contextually-relevant survey creation that provides technological contextualization to otherwise context-excluded research [24], [25]. Finally, freelisting can aid in cross-cultural research by affording IS researchers a valuable tool with which to compare similarities and differences across cultures.

The paper is organized as follows. First, we give a brief overview of ethnography, the cultural domain, and freelisting. Then, we explain the freelist technique. Next, we discuss how to analyze a freelist via an example in the context of adopting etextbooks. We conclude with a discussion of how to optimize the use of freelists in IS research, and provide several benefits and research recommendations for researchers.

\section{Ethnographic research, the cultural domain, and freelisting}

\subsection{Ethnographic Research}

Ethnographic research involves systematically documenting "the culture of the setting (the socially acquired and shared knowledge available to the participants or members of the setting) to account for the observed patterns of human activity" [25, p. 539]. Ethnography is often thought of as both a product and a process. The product being the story, or 'thick description' about the community and people under study, and the process being the interaction with, and the tools used to collect the data. [27]-[30].
Ethnographic research has conventionally been associated with an extensive period of a study during which the researcher immerses him/herself into a community [9], [26]. Ethnographers, in a traditional sense, inhabit and become a member of a community with the goal to observe, participate in, and document as much as possible over periods often lasting one to three years (i.e., participant-observation) [9], [28].

Modern day ethnographers, however, spend much less time in the field [28]. Instead, modern ethnographers tend to focus their studies on a particular topic and dimension of culture [28]. In other words, rather than spending several years 'going native,' modern ethnographers adopt and guide their research through a cultural theme. Although these 'focused ethnographies' may require less time, they necessitate more rigorous research methods and tools, more attention on the culture under investigation, and greater provision for the domain in which the cultural theme exists [22], [28].

In the IS discipline, ethnographic research began in the late 1970s and saw some initial application into the 1980s [31]-[33]. In the 1990s, ethnography became more widely accepted as the value of ethnography became more recognizable [9]. For example, in a seminal IS paper, Orlikowski [6] used a variety of ethnographic techniques to present the Structurational Model of Technology which describes the interactions between and the impact of technology on individuals and organizations. Since then, ethnography has become somewhat more commonplace in top IS journals [e.g., 34, 35, 36]. Notably, Venkatesh et al. [23], in an important paper on mixed-methods research, recognizes ethnography as a fruitful means to complement a case study or a quantitative method.

While this collection of ethnographic research in IS has been beneficial, we believe that a more indepth understanding of ethnographic methods can provide additional value to IS researchers. Specifically, as opposed to the conventional wisdom that ethnography in IS research still requires 'going native' and spending a great deal of time in the field, we advocate for more focused and less time consuming ethnographies. Freelisting is a valuable technique used to yield such focused ethnographies.

\begin{tabular}{|l|l|}
\hline \multicolumn{2}{|c|}{ Table 1. An overview of ethnography, cultural domain, and freelisting } \\
\hline \multicolumn{1}{|c|}{ Term } & \multicolumn{1}{c|}{ Description } \\
\hline Ethnography & $\begin{array}{l}\text { Involves systematically documenting "the culture of the setting (the } \\
\text { socially acquired and shared knowledge available to the participants or } \\
\text { members of the setting) to account for the observed patterns of human } \\
\text { activity" [26, p. 539]. }\end{array}$ \\
\hline Cultural Domain & $\begin{array}{l}\text { "A set of related words, concepts, or statements about a single theme" } \\
\text { [40, p. 368]. The words, concepts, or statements must be made by the } \\
\text { community members themselves. Otherwise, the cultural domain will } \\
\text { reflect the researcher's ideas, not the community members'. }\end{array}$ \\
\hline Freelisting & $\begin{array}{l}\text { A cognitive anthropological technique that enables the researcher to } \\
\text { extract a set of items, or a list, that exists in a cultural domain. The list } \\
\text { represents how individuals interpret the world. }\end{array}$ \\
\hline
\end{tabular}


Before discussing freelisting in great detail, one must further understand how culture is conceptualized and the role of the cultural domain.

\subsection{Culture and the cultural domain}

Culture typically falls under two perspectives: the etic and the emic. The etic approach assumes culture exists from an outside researcher's point of view. The emic approach positions culture from the native's point of view [2], [22], [37]. Ethnographers strive to uncover the language and perspective of the community members being studied, and therefore espouse an emic perspective of culture [38], [39]. The cultural domain falls under in the emic tradition and is highly important when conducting ethnographic research.

The cultural domain has been defined as "a set of related words, concepts, or statements about a single theme" [40, p. 368]. The words, concepts, or statements published by the researcher must be made by the community members themselves. Otherwise, the cultural domain will reflect the researcher's ideas (i.e., etic), rather than the community members' (i.e., emic) [40]. This means the researcher must be in tune with the language and concepts of the community members, and therefore must elicit such items using the community members' own words. This enables researchers to discover how individuals think about and subscribe meaning to the world in which they live [41]. Some examples of cultural domains in anthropology have included categories of plants used for medical purposes [19], [20], the most common types of brands typically eaten in a community [42], and categories of widely-used cultural remedies to illnesses [43].

Overall, there are two general questions ethnographers want to know about a cultural domain: (1) What belongs in it? and (2) How are its contents structured? [44]. Answering these questions gives researchers a solid idea about how individuals in a particular culture interpret the world around them. Freelisting is an ethnographic method that can provide answers to both of these questions.

\subsection{Freelisting}

Freelisting is a technique used in anthropology that enables a researcher to extract a set of items, or a list, that exists in a cultural domain [40]. The resulting list represents how individuals interpret the world [41]. When conducting a freelist, the researcher asks several community members (one-ata-time) to list items related to a pre-established cultural domain [40]. The community member then lists the items freely in whatever order that comes to mind [19]. The researcher then records the items in a list, while also taking thorough notes about unfamiliar terms or unexpected responses [41]. This process is repeated several times in order to capture the freelists of as many individual community members as possible. During the freelist, the researcher also notes demographic variables such as age, gender, ethnicity, cultural status and expertise, and so on [41].

The resulting freelist represents an index of items in the specific cultural domain. For example, Weller [45] asked women in the United States and Guatemala to list a set of illness terms, and compared the answers to inquire into the cultural similarities and differences between the two countries. In doing so, Weller [45] was able to understand how woman describe and interpret common illnesses across two different cultures.

Quinlan [19] underscores that there are three important assumptions researchers should know when beginning a freelist. First, it is assumed that the freelister (i.e., the community member who freelists) develops the list in order of his or her familiarity. For example, when asked to list the closeness of family members, the freelister will likely list a spouse before a cousin. Second, if a freelister is well-versed in a topic, he or she will list more items than a freelister who knows less about a subject. Third, the most common items that appear among every freelister are considered the most "locally prominent items" [19]. In other words, the generated list of topics reveals that the most common items are the most culturally salient.

Research using the freelisting technique is essentially non-existent in IS research. For example, a recent search of the Association of Information Systems Electronic Library using the search term "freelist" resulted in zero results. Using the terms "free list" produced 10 total results, of which only one manuscript was deemed relevant to the freelisting technique upon detailed scrutiny [46]. The one relevant article uses a free listing technique in the context of innovation in developing regions to "tell us their daily problem-solving tasks, information needs and constraints, and information technologies used" [9, p. 7]. However, the freelisting procedure used in the study is not discussed in detail.

Outside of the IS discipline, but in the context of information technology, there have been several studies that have used the freelisting technique. In one example, Srinivasan [47] employs freelists to generate culturally relevant items in the design of a computer system that enables culturally and 
community-focused goals. Similarly, Srinivasan [48] utilizes freelisted items to create communityinformed content for designing information systems characterized by community-focused design.

\subsection{Importance considerations when freelisting}

In a seminal paper on freelisting, Quinlan [19] suggests that there are five important considerations when conducting freelists. These involve becoming familiar with the following topics: (1) To freelist or not to freelist, (2) Oral or written freelists, (3) Focusing the cultural domain, (4) Analyzing freelists, and (5) Triangulating freelists with interviews. For the purposes of the present analysis, and using Quinlan's guidance, we focus on the fourth and fifth aspect of Quinlan's [19] items: analyzing freelists and triangulating freelists. In doing so, we assume that the researcher has already decided to freelist, to conduct a written freelist, and has focused the cultural domain. To illustrate the more substantive steps of analyzing and triangulating freelists, we use an example of a written freelist conducted in the cultural domain of undergraduates adopting etextbooks at a four year research university.

\section{Steps in analyzing freelists}

As noted above, freelists provide insights into the cultural salience (i.e., cultural importance) of a group of people [19]. As such, the analysis involved in freelisting is often called salience analysis. Salience analysis enables the researcher to analyze the frequency of a topic mentioned so as to ultimately reach a salience score, which is a measure of the importance of an item in a cultural domain [19]. The salience score is weighted for list position and denotes how frequently an item was mentioned among the freelisters. Using the procedure outlined by Quinlan [19], we provide step-by-step instructions on how to reach a salience score. We do so through a brief example of e-textbook adoption by undergraduate students. Table 2 provides an overview of the steps in analyzing freelists.

\subsection{Overview of research example}

The example research used here is based on an ongoing study by the present authors. The first author conducted an online, written freelist sent to undergraduates enrolled in a four-year research university. The goal of the freelist is to understand why students may adopt electronic textbooks. A URL to the freelist was sent to approximately 400 undergraduate students. The link contained several demographic questions such as age, gender, and status in college. The students then answered the question: "Please list reasons why students at your school would adopt an electronic textbook." Below, we discuss the analyzation and triangulation steps from Quinlan [19] process, using the freelist data collected online.

\subsection{Step 1: Categorize the freelists}

The first step in analyzing freelists is categorizing the information provided by each individual [19]. In other words, researchers should attempt to recognize patterns across individual responses and classify the responses into an abstracted category. While the initial question asked to the individual may be perceived as simple, the individual may provide a lengthy response [19]. For example, in our study, one subject responded that "E-textbooks are easier for students to utilize. You do not need to carry around the physical book. You can access it anywhere." This eventually led to the category "accessibility," discuss below.

This categorization process may be tedious. There are several helpful computer programs to aid in this categorization process (e.g., NVivo, a popular qualitative analysis tool). Alternatively, there are several other qualitative methods used to categorize data [see 37, 45, 46 for more information].

\subsection{Step 2: Calculate the salience score for each freelister}




\begin{tabular}{|l|l|l|}
\hline \multicolumn{3}{|c|}{ Table 2. Steps in analyzing freelists } \\
\hline \multicolumn{1}{|c|}{ Step } & \multicolumn{1}{|c|}{ Description } & \multicolumn{1}{c|}{ Outcome } \\
\hline $\begin{array}{l}\text { Step 1: } \\
\text { Categorize the } \\
\text { Freelists }\end{array}$ & $\begin{array}{l}\text { The researcher classifies the responses of each individual into an } \\
\text { abstracted category that grasps the main idea of the response of } \\
\text { each community member. }\end{array}$ & $\begin{array}{l}\text { Multiple } \\
\text { categories ready } \\
\text { for analysis }\end{array}$ \\
\hline $\begin{array}{l}\text { Step 2: Calculate } \\
\text { the Salience }\end{array}$ & $\begin{array}{l}\text { The researcher ranks the items in an individual's freelist. To do } \\
\text { so, the researcher ranks each item inversely. The researcher then } \\
\text { divides the ranking by the number of total items listed by the } \\
\text { individual to reach a total salience score (S), which gives the } \\
\text { Freelister }\end{array}$ & $\begin{array}{l}\text { Salience score (S) } \\
\text { for each freelister }\end{array}$ \\
\hline $\begin{array}{l}\text { Step 3: Calculate } \\
\text { the average } \\
\text { Salience Value } \\
\text { for each item in } \\
\text { all freelists }\end{array}$ & $\begin{array}{l}\text { The researcher sums each of the Salience scores for each item for } \\
\text { every freelister. Then the researcher divides by the total number } \\
\text { of freelisters in the sample. The mean Salience score indicates the } \\
\text { item with the most cultural salience. }\end{array}$ & $\begin{array}{l}\text { Mean salience } \\
\text { score for each } \\
\text { item }\end{array}$ \\
\hline $\begin{array}{l}\text { Step 4: } \\
\text { Identifying a } \\
\text { Community } \\
\text { Member's } \\
\text { Domain Expertise }\end{array}$ & $\begin{array}{l}\text { Then research then tabulates the number of items listed by each } \\
\text { freelister. Doing so provides insight into the most knowledgeable } \\
\text { community members. This is because it is assumed that the } \\
\text { individuals with the most experience in a cultural domain tend to } \\
\text { list the most items. }\end{array}$ & $\begin{array}{l}\text { Insight into the } \\
\text { most } \\
\text { knowledgeable } \\
\text { community } \\
\text { member(s) }\end{array}$ \\
\hline
\end{tabular}

Once the categories have been developed, the researcher then ranks the items in an individual's freelist inversely [19]. In other words, the last item in an individual's list receives a score of 1 . The second to last item in an individual's list receives a score of 2 , and so on. For example, in Table 3, a subject lists reasons why students in his/her university may adopt e-textbooks. The individual provided three reasons, categorized as: cheaper price, accessibility of the etextbook, and e-textbook expiration, (meaning that students do not have to determine whether to sell the textbook back to the on-campus bookstore, an offcampus bookstore, or online.)

Once the list is ranked in reverse, the next step is to divide the ranking by the number of total items listed by the individual to reach a total salience score. This gives the researcher an idea of the cultural importance of a specific item [19]. For example, in Table 3, the "cheaper price" category is ranked as a three. There are also three total items listed by this particular student. In this case, the researcher would

\begin{tabular}{|c|c|c|}
\hline Reason & $\begin{array}{l}\text { Inverted Rank/ } \\
\text { Total Listed }\end{array}$ & $\begin{array}{l}\text { Salience } \\
\text { score }(S) \\
\end{array}$ \\
\hline Cheaper Price & $3 / 3$ & 1 \\
\hline Accessibility & $2 / 3$ & 0.667 \\
\hline $\begin{array}{l}\text { Less Hassle } \\
\text { During } \\
\text { Sellback }\end{array}$ & $1 / 3$ & 0.333 \\
\hline
\end{tabular}

divide three by three and receive a salience score of one. The next item is "accessibility," which receives a salience score of 0.667 (two divided by three). For this particular individual, the cultural salience of etextbooks having a cheaper price is higher than that of e-textbooks being accessible for this freelister subject. In other words, having a cheaper price is more important than the other two reasons for this individual.

\subsection{Step 3: Calculate the average salience value for each item in all freelists}

The next step is to calculate a mean salience score for each of the items across every freelister [19]. To do so, the researcher sums each salience score for each item for each individual freelister, and then divides by the total number of freelisters in the sample [19]. Table 4 shows a basic example of this process.

In Table 4, there are three total freelisters. Each listed several reasons for e-textbook adoption. The salience score for each of the three is displayed, followed by the sum of the salience scores. The average salience score is then calculated for each item. The average salience score indicates the item with the most cultural salience (not individual salience). In this example, with a sample size of three, "accessibility" is the most culturally salient reason students at this particular research university would adopt an e-textbook, followed by "cheaper price" and "less hassle during sellback". 


\begin{tabular}{|l|c|c|c|c|c|}
\hline \multicolumn{7}{|c|}{ Table 4. Mean salience score for each reason to adopt an e-textbook } \\
\hline & \multicolumn{3}{|c|}{ Freelister } & Sum of Reason & Mean Salience Score $(n=3)$ \\
\hline Reason & 1 & 2 & 3 & & \\
\hline Accessibility & 0.667 & 0.75 & 1 & 2.417 & 0.806 \\
\hline Cheaper Price & 1 & 1 & & 2 & 0.667 \\
\hline Less Hassle During Sellback & 0.333 & 0.50 & 0.667 & 1.5 & 0.5 \\
\hline Can Purchase Book Online & & & 0.333 & 0.333 & 0.222 \\
\hline Easily Searchable for Keywords & & 0.25 & & 0.25 & 0.167 \\
\hline
\end{tabular}

It is important to note that the process for identifying which items are not culturally salient is not standard [19]. That is, there is no agreed upon cutoff value for the mean salience score. The recommendation is to look for "visible breaks in the data that make good margins" [29, p. 8].

\subsection{Step 4: Identifying a community member's domain expertise (a step towards triangulation)}

The next step is to tabulate the number of items listed by each freelister. Doing so provides insight into the most knowledgeable community members in a particular cultural domain [19]. This is because it is assumed that the individuals with the most experience in this domain tend to list the most items [19]. Identifying these individuals could then enable a researcher to triangulate the data by conducting follow-up interviews during which these subjects could elaborate more on the items, the details of their significance, and potentially interesting relationships among the items.

Quinlan [19] advocates that the most effective way to determine the most knowledgeable community members is to create an individual-byitem matrix. Table 5 shows an example of an individual-by-item matrix using the data from the example about e-textbooks. Of course, a larger sample size would warrant better inquiry.

\section{Potential problems and solutions to freelisting in IS research}

The spirit of the freelisting technique is to dive deeper into a cultural domain [19], [41] and to quantify and analyze how community members in that cultural domain understand and navigate their world [19]. With this comes with a major problem, which is the understanding of a cultural domain under investigation may still be subject to the researcher's own biases. In other words, a researcher may unknowingly instill his/her own beliefs and/or interpretations into the analysis [49]. For example, the first step when analyzing a freelist is to categorize the words and phrases listed by the community members. When doing so, the researcher sifts through each subject's statements and standardizes such statements according to his/her own judgement [19]. This abstraction process therefore inherently involves the researcher integrating his/her own interpretations and preexisting knowledge into the analysis in order to craft the freelist. This process can fundamentally conflict with the emic understanding of culture.

To counterbalance the potential bias introduced during this interpretive process, it is highly recommended that freelists be cross-referenced with interviews with community members in the cultural domain, and subsequently refined where deemed necessary by the subjects. For example, Quinlan [19] discusses using focus groups to provide more "emic authority" to the study. Quinlan mentions that in one instance, the twenty-one item freelist was given to and debated by the focus group comprised of community members, who, after much discourse, narrowed the list and provided much-needed clarity on the original categorization [19].

\begin{tabular}{|c|c|c|c|c|}
\hline \multicolumn{5}{|c|}{ Table 5. Individual-by-item matrix } \\
\hline & & $\overline{\text { eelt }}$ & & Frequency \\
\hline Reason & 1 & 2 & 3 & \\
\hline Accessibility & 1 & 1 & 1 & 3 \\
\hline Cheaper Price & 1 & 1 & 0 & 2 \\
\hline Less Hassle During Sellback & 1 & 1 & 1 & 3 \\
\hline Can Purchase Book Online & 0 & 0 & 1 & 1 \\
\hline Easily Searchable for Keywords & 0 & 1 & 0 & 1 \\
\hline Total Reasons & 3 & 4 & 3 & 13 \\
\hline
\end{tabular}


In the present e-textbook example, several subjects could be called in for a focus group session after creating the initial freelist. The researchers could identify these students using the individual-byitem matrix, or they could be randomly selected. Doing so would enable the students to discuss amongst each other and provide clarification about the list and the shared meaning of the items. In this example, the number one reason for adopting etextbooks in this example study is accessibility. A group of students could elaborate on this term and identify several dimensions of accessibility and its relationship to the act of studying. Overall, following-up the freelists with interviews and/or focus groups with community members can provide more valuable clarity on the freelists, as well as add richer meaning to the items on the lists.

\section{Benefits for IS research}

Meyers [9] cited several benefits of ethnographic research in IS, including potential for developing deeper insights into novel IS topics and using ethnography to challenge assumptions in widely-used models and to critically examine findings published research. We believe that freelists can also provide additional benefits and promising avenues for IS research and researchers.

\subsection{Revisiting long-established theories}

The freelist technique can equip IS researchers with a novel methodological tool to reexamine longstanding research assumptions and conclusions. For example, in a 2007 special issue of the Journal of the Association for Information Systems (JAIS) that centered on a discourse about technology acceptance research [50], Benbasat and Barki [51] note that constructs embedded in technology acceptance, such as perceived ease of use and perceived usefulness have been treated as "black boxes that very few have tried to pry open," and that "we are now left in a state of methodological vacuum."

Following this, we argue that the freelisting method may serve as an innovative technique that IS researchers could use to revisit comprehensive theories such as the technology acceptance model, and concepts such as perceived ease of use and perceived usefulness in order to uncover fresh insights into technology adoption, for example. Doing so would enable IS researchers to pry open the black box of technology, and to revisit and revise seemingly solidified models, and the foundational assumptions underlying these models, so that they are relevant in today's digital business landscape.

\subsection{Survey creation}

Freelists have also been deemed as a way to provide information that can be used in culturallyfocused survey creation [41]. For example, when undergoing a mixed methods approach, a researcher could begin by freelisting community members in a specific cultural domain. After finalizing the freelist, the researcher could then use the insight gained from the community members to craft a survey derived from this emic insight. In doing so, IS researchers can dive a bit deeper into the context in which they are

\begin{tabular}{|l|l|}
\hline \multicolumn{1}{|c|}{ Benefit } & \multicolumn{1}{c|}{ Dable 6. Benefits for IS research } \\
\hline $\begin{array}{l}\text { Revisiting Long- } \\
\text { Established Theories }\end{array}$ & $\begin{array}{l}\text { Freelisting can equip IS researchers with a novel methodological } \\
\text { tool to reexamine long-standing research assumptions and } \\
\text { conclusions. }\end{array}$ \\
\hline Survey Creation & $\begin{array}{l}\text { Freelists have been deemed a way to provide information that } \\
\text { can be used in culturally specific survey creation. }\end{array}$ \\
\hline $\begin{array}{l}\text { Strengthening Mixed } \\
\text { Methods }\end{array}$ & $\begin{array}{l}\text { The freelist technique strongly lends itself to mixed methods } \\
\text { research. When conducting a freelist, a researcher is } \text { expected to } \\
\text { undertake multiple methods so that the emic essence of the } \\
\text { technique is preserved. }\end{array}$ \\
\hline Cross Cultural Insight & $\begin{array}{l}\text { Freelists can provide researchers with a tool to compare } \\
\text { similarities and differences about how cultures perceive and } \\
\text { interact with the world. }\end{array}$ \\
\hline $\begin{array}{l}\text { Contextualizing IS } \\
\text { Research }\end{array}$ & $\begin{array}{l}\text { The freelisting technique can provide IS researchers with a tool } \\
\text { to consciously consider the context in which the technology } \\
\text { resides before conducting research. }\end{array}$ \\
\hline
\end{tabular}


studying, and coupled with preexisting constructs, can craft a more relevant and accurate survey instrument. Moreover, the freelisting technique can also aid IS researchers in refining existing survey constructs and tools so that they are contextually relevant in the new millennium.

\subsection{Mixed methods}

According to Venkatesh et al. [23], "mixed methods research has been termed the third methodological movement, with quantitative and qualitative methods representing the first and second movements respectively" (p. 22). The freelist technique lends itself well to this burgeoning third methodological movement. In fact, at its core, when conducting a freelist, a researcher is expected to undertake multiple methods so that the emic essence of the research is preserved [19]. Because of its fundamental core of triangulating the freelists with interviews, the freelist technique is an efficient and accessible method that can help provide IS researchers with a means to uncover a complete picture of technology in several research streams using multiple methods.

\subsection{Cross cultural insight}

When understanding differences in technology across cultures, the context of the community members within the culture is important to recognize [11]. In anthropology, it is common to perform freelisting in two or more cultural domains in multiple countries, and then compare and contrast these domains. In doing so, researchers can elucidate similarities and differences about topic of study in order to arrive at a more generalizable and holistic understanding of social reality [45].

For example, an IS researcher could use freelisting to perform cross cultural research about technology-induced stress [52] in two (or more) cultures and/or countries. This could culminate in the comparison of the finalized freelists to understand any similarities and differences that exist in how the community members in different contexts perceive technology-induced stress.

\subsection{Contextualizing IS research}

IS research often assumes that technology is an exogenous force that induces reactions from individuals, organizations, and societies [53]. However, technology can also be thought of as a construct based on human interpretation, and therefore, how technology is interpreted is heavily dependent on the context in which it is researched [53]. This emergent and entangled perspective of technology directly relates to the emic umbrella which covers much of cultural anthropology and freelisting. In this sense, freelisting can provide IS researchers with a tool to put the context back into the technology. So much of the context in today's IS research is often absent or marginally discussed. Using the freelist method, IS researchers can being their study with context in mind and work from a contextually-grounded investigation to a generalized one, as opposed to vice versa.

\section{Conclusion}

The Information Systems discipline is often praised for a multiplicity of research methods [9], [23], and has celebrated ethnography as a fruitful method to uncover substantial insight in an information systems context [9]. While ethnographic research has been commended as valuable, it remains underutilized [13]. This paper proposes the use of freelisting [19], a widely used ethnographic technique in anthropology, as a respectable tool for IS researchers to use to conduct focused ethnographies and to collect data easily and quickly. The paper provides an overview of ethnography and details the freelist technique's role in ethnography. The paper discusses how freelists should be conducted and analyzed, and provides several benefits for IS research and IS researchers. Overall, freelisting can help provide deeper and richer insight into information systems phenomena.

\section{References}

[1] G. Burrell and G. Morgan, Sociological Paradigms and Organisational Analysis: Elements of the Sociology of Corporate Life. Routledge, 2017.

[2] S. Gregor, "The Nature of Theory in Information Systems," Management Information Systems Quarterly, vol. 30, no. 3, Sep. 2006, pp. 611-642.

[3] R. Hirschheim and H. K. Klein, "Four Paradigms of Information Systems Development," Communications of the ACM, vol. 32, no. 10, Oct. 1989, pp. 1199-1216.

[4] A. S. Lee, "Integrating Positivist and Interpretive Approaches to Organizational Research," Organization Science, vol. 2, no. 4, Nov. 1991, pp. 342-365. 
[5] M. L. Markus and D. Robey, "Information Technology and Organizational Change: Causal Structure in Theory and Research," Management Science, vol. 34, no. 5, May 1988, pp. 583-599.

[6] W. J. Orlikowski, "The duality of technology: Rethinking the concept of technology in organizations," Organization Science, vol. 3, no. 3, 1992, pp. 398-427.

[7] R. L. Baskerville and M. D. Myers, "Design ethnography in information systems," Information Systems Journal, vol. 25, no. 1, Jan. 2015, pp. 2346.

[8] M. D. Myers, "Critical Ethnography in Information Systems," in Proceedings of the IFIP TC8 WG 8.2 International Conference on Information Systems and Qualitative Research, London, UK, UK, 1997, pp. 276-300.

[9] M. D. Myers, "Investigating Information Systems with Ethnographic Research," Communications of the Association of Information Systems, vol. 2, no. 1, Dec. 1999.

[10] D. Avison and G. Fitzgerald, "Reflections and opinions on 25 years with the ISJ," Information Systems Journal, vol. 22, no. 3, May 2012, pp. 179 193.

[11] D. Leidner and T. Kayworth, "A Review of Culture in Information Systems Research: Toward a Theory of Information Technology Culture Conflict," Management Information Systems Quarterly, vol. 30, no. 2, Jun. 2006, pp. 357-399.

[12] J. Mingers, "The paucity of multimethod research: a review of the information systems literature," Information Systems Journal, vol. 13, no. 3, Jul. 2003, pp. 233-249.

[13] A. Brown, "The place of ethnographic methods in information systems research," International Journal of Multiple Research Approaches, vol. 8, no. 2, Oct. 2014, pp. 166-179.

[14] Lynda J. Harvey and Michael D. Myers, "Scholarship and practice: the contribution of ethnographic research methods to bridging the gap," Information Technology \& People, vol. 8, no. 3, Sep. 1995, pp. 13-27.

[15] J. Rennecker, "Updating Ethnography to Investigate Contemporary Organizational Forms," The Handbook of Information Systems Research, 2004, pp. 133-149.

[16] P. Leonardi, "When Flexible Routines Meet Flexible Technologies: Affordance, Constraint, and the Imbrication of Human and Material Agencies,"
Management Information Systems Quarterly, vol. 35, no. 1, Mar. 2011, pp. 147-167.

[17] M. N. Ravishankar, S. L. Pan, and M. D. Myers, "Information technology offshoring in India: a postcolonial perspective," European Journal of Information Systems, vol. 22, no. 4, Jul. 2013, pp. 387-402.

[18] N. M. Henley, "A psychological study of the semantics of animal terms," Journal of Verbal Learning and Verbal Behavior, vol. 8, no. 2, Apr 1969, pp. 176-184.

[19] M. Quinlan, "Considerations for Collecting Freelists in the Field: Examples from Ethobotany," Field Methods, vol. 17, no. 3, Aug. 2005, pp. 219-234.

[20] M. B. Quinlan and R. J. Quinlan, "Modernization and Medicinal Plant Knowledge in a Caribbean Horticultural Village," Medical Anthropology Quarterly, vol. 21, no. 2, Jun. 2007, pp. 169-192.

[21] A. K. Romney and R. G. D'andrade, "Cognitive Aspects of English Kin Terms," American Anthropologist, vol. 66, no. 3, Jun. 1964, pp. 146170 .

[22] M. Agar, The professional stranger: an informal introduction to ethnography. Academic Press, 1980.

[23] V. Venkatesh, S. Brown, and H. Bala, "Bridging the Qualitative-Quantitative Divide: Guidelines for Conducting Mixed Methods Research in Information Systems," Management Information Systems Quarterly, vol. 37, no. 1, Mar. 2013, pp. 21-54.

[24] H. Klein and M. Myers, "A Set of Principles for Conducting and Evaluating Interpretive Field Studies in Information Systems," Management Information Systems Quarterly, vol. 23, no. 1, Dec. 1999, pp. 67-93.

[25] S. Sarker, X. Xiao, and T. Beaulieu, "Guest Editorial: Qualitative Studies in Information Systems: A Critical Review and Some Guiding Principles," Management Information Systems Quarterly, vol. 37, no. 4, Dec. 2013, pp. iii-xviii.

[26] J. Van Maanen, "The Fact of Fiction in Organizational Ethnography," Administrative Science Quarterly, vol. 24, no. 4, 1979, pp. 539550.

[27] C. Geertz, The Interpretation Of Cultures. Basic Books, 1973.

[28] M. D. LeCompte and J. J. Schensul, Designing \& Conducting Ethnographic Research: An Introduction. Rowman Altamira, 2010. 
[29] G. Walsham, "Interpretive Case Studies in IS Research: Nature and Method," in Qualitative Research in Information Systems, London, SAGE Publications, Ltd, 2002, pp. 100-113.

[30] G. Walsham, "Doing interpretive research," European Journal of Information Systems, vol. 15, no. 3, Jun. 2006, , pp. 320-330.

[31] L. A. Suchman, Plans and Situated Actions: The Problem of Human-machine Communication. New York, NY, USA: Cambridge University Press, 1987.

[32] E. H. Wynn, Office Conversation as an Information Medium. Department of Anthropology, University of California, 1979.

[33] S. Zuboff, In The Age Of The Smart Machine: The Future Of Work And Power. Basic Books, 1988.

[34] M. Mazmanian, M. Cohn, and P. Dourish, "Dynamic Reconfiguration in Planetary Exploration: A Sociomaterial Ethnography," Management Information Systems Quarterly, vol. 38, no. 3, Sep. 2014, pp. 831-848.

[35] P. Almklov, T. Østerlie, and T. Haavik, "Situated with Infrastructures: Interactivity and Entanglement in Sensor Data Interpretation," Journal of the Association of Information Systems, vol. 15, no. 5, May 2014.

[36] A. Greenhill and G. Fletcher, "Laboring Online: Are There 'New' Labor Processes In Virtual Game Worlds?," Journal of the Association of Information Systems, vol. 14, no. 11, Nov. 2013.

[37] P. Kanawattanachai and Y. Yoo, "The Impact of Knowledge Coordination on Virtual Team Performance over Time," Management Information Systems Quarterly, vol. 31, no. 4, Nov. 2008, pp. 783-808.

[38] H. R. Bernard, Research Methods in Anthropology: Qualitative and Quantitative Approaches. Rowman Altamira, 2011.

[39] C. C. Gravlee, "Ethnic Classification in Southeastern Puerto Rico: The Cultural Model of 'Color,'” Social Forces, vol. 83, no. 3, Jun. 2005, pp. 949-970.

[40] S. C. Weller, "Structured interviewing and questionnaire construction," Handbook of Methods in Cultural Anthropology, 2000.

[41] R. T. Trotter and J. J. Schensul, "Methods in Applied Anthropology," in Handbook of Methods in Cultural Anthropology, AltaMira Press, 1998, pp. 691-736.
[42] J. Brewer, Ethnography, 1 edition. Buckingham, Open University Press, 2001.

[43] R. T. Trotter, "A Survey of Four Illnesses and Their Relationship to Intracultural Variation in a MexicanAmerican Community," American Anthropologist, vol. 93, no. 1, 1991, pp. 115-125.

[44] "Lance Gravlee - Free Lists in Ethnographic Research." Available: http://gravlee.org/ang6930/freelists.htm.

[45] S. C. Weller, "Cross Cultural Concepts of Illness: Variation and Validation," American Anthropologist, vol. 86, no. 2, Jun. 1984, pp. 341351.

[46] Y. Deng and K. Chang, "Task-Technology Fit for Low-Literate Consumers: Implications for IS Innovations in the Developing Regions," ICIS 2013 Proceedings, Dec. 2013.

[47] R. Srinivasan, "Indigenous, ethnic and cultural articulations of new media," International Journal of Cultural Studies, vol. 9, no. 4, Dec. 2006, pp. 497518.

[48] R. Srinivasan, "Ethnomethodological architectures: Information systems driven by cultural and community visions," Journal of the Association for Information Science and Technology, vol. 58, no. 5, Mar. 2007, pp. 723-733.

[49] S. C. Weller and A. K. Romney, Systematic Data Collection. SAGE, 1988

[50] R. Hirschheim, "Introduction to the Special Issue on 'Quo Vadis TAM - Issues and Reflections on Technology Acceptance Research,'” Journal of the Association of Information Systems, vol. 8, no. 4, Apr. 2007.

[51] I. Benbasat and H. Barki, "Quo vadis TAM?," Journal of the Association of Information Systems, vol. 8, no. 4, Apr. 2007.

[52] T. S. Ragu-Nathan, M. Tarafdar, B. S. Ragu-Nathan, and Q. Tu, "The Consequences of Technostress for End Users in Organizations: Conceptual Development and Empirical Validation," Information Systems Research, vol. 19, no. 4, Aug. 2008, pp. 417-433.

[53] W. J. Orlikowski, "The sociomateriality of organisational life: considering technology in management research," Cambridge Journal of Economics, vol. 34, no. 1, Jan. 2010, pp. 125-141. 